\title{
SUPPLY RISK MITIGATION OF SMES THROUGH LEVERAGING SOCIAL CAPITAL: DEVELOPMENT AND VALIDATION OF A MEASUREMENT INSTRUMENT
}

\author{
*Priyabrata Chowdhury ${ }^{1}$, *Kwok Hung Lau and *Siddhi Pittayachawan \\ "School of Business IT \& Logistics, RMIT University
}

\begin{abstract}
Literature on supply risk management has consistently promoted the use of network capital to mitigate supply risk of small and medium-sizedenterprises (SMEs). Many scholars in supply chain management have suggested that structural, relational and cognitive dimensions of social capital in both the buyer-supplier network and the network of peers within a cluster can play an influential role in mitigating the supply risk of SMEs. Although research interest in supply risk management through a social capital approach is growing, so far no study has been directed towards the development of an instrument to measure network capital in the context of SMEs. To supplement such inadequacy, this study conceptualizes, develops and validates four constructs of network resources/practices, namely, buyer-supplier social capital, cluster social capital, buyer-supplier integration and cluster cooperation, and supply risk construct. In developing the instrument, a rigorous process employing literature review, focus groups discussion, opinions of academics and experts, and agreement survey has been followed. Using the survey data collected from the apparel SMEs of Bangladesh for validation, the findings of the study suggest that the proposed instrument is a set of reliable and valid measures of the above-mentioned constructs. Therefore, it can be subsequently applied in other studies through a contextual modification as a means to examine various theoretical and conceptual models.
\end{abstract}

Keywords: Measurement, Social capital, Supply risk, Small and medium-sized enterprises

\section{Introduction}

In today's global business environment, supply chains have become more complex in structure and challenging in management (Ambulkar et al. 2015; Cheng et al. 2012). Consequently, firms are exposed to higher supply risks in recent years (Christopher et al. 2011). Supply risks can be defined as the probable deviations in the inbound supply from the initial overall objectives that may result in incomplete or unfinished orders(Kumar et al. 2010). Supply risks incur significant financial and non-financial losses for organizations who fail to protect themselves against the risks (Kim \& Vonortas 2014; Wiengarten et al. 2013). In general, the impact of supply risks on firm performance is more severe for small and medium-sized enterprises (SMEs) than large corporations (Ellegaard 2008; Hendricks \& Singhal 2005; Hendricks \& Singhal 2003). For instance, through a comparative study, Hendricks andSinghal (2005) reported that similar supply risk reduces operating income of SMEs by $75.77 \%$ more than that of large enterprises.
Although SMEs are more vulnerable to supply risks than large enterprise, focus of previous studies on supply risks or supply risk management has been placed mainly on large corporations(Kim \& Vonortas 2014; Ellegaard 2008). Moreover, the majority of these studies primarily recommended holding buffer stock, developing supplier, and ensuring formal process for mitigating supply risks. Each of these measures needs either considerable resources or strong position power to influence suppliers. These measures are usually beyond the capabilities of SMEs due to their limited resources and managerial skills (Chowdhury 2012; Prasad et al. 2012). As an alternative avenue, many authors proposed leveraging social capital to mitigate supply risks of SMEs (Prasad et al. 2012; Jansen et al. 2011; Villa \& Antonelli 2009). The authors argued that social capital, which exists within the horizontal and vertical network of an organization, can help develop SMEs' ability in mitigating supply risks. However, social capital requires less financial investment (Uphoff 2000) which overcomes the barrier of resource deficiency of 
SMEs. While different studies suggested the use of different types of social capital to mitigate supply risk, Chowdhury et al. (2016) mentioned, through an extensive literature review, that two types of social capital are particularly relevant to SMEs. They include buyer-supplier social capital resources gained via the network of sourcing SMEs and their suppliers - and cluster social capital resources leveraged through the network of similar SMEs within the same geographical cluster. The authors also contended that buyer-supplier integration and cluster cooperation mediate the relationship between (a) buyer-supplier social capital and supply risk, and (b) cluster social capital and supply risk respectively, as depicted in
Figure 1. To validate the relationships between the constructs, they called for future research to investing ate these associations. While leveraging social capital to mitigate supply risks of SMEs is suggested in the literature, no research so far has been directed towards the development of a survey instrument to measure the above-mentioned network resources and supply risk in the context of SMEs. Given that operational measures of a construct depend on the size and context of the firm (Venkatraman 1989), it is important to develop an instrument to measure the above-mentioned constructs in the context of SMEs before testing the relationships.

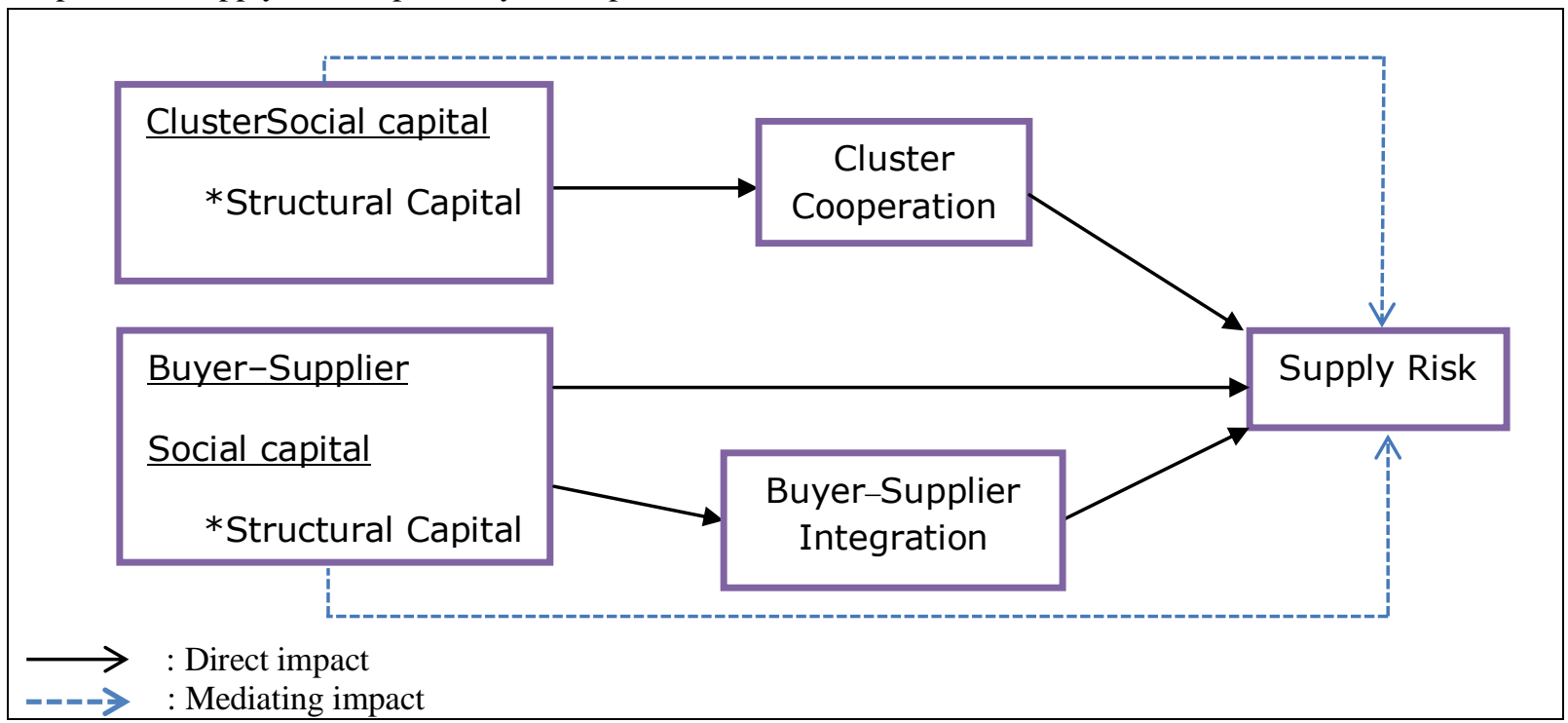

Figure 1: A conceptual framework of network resources and supply risk (Source: Chowdhury et al. (2016, p.

40)

The primary purpose of this study, therefore, is to develop an instrument to measure five constructs, namely, buyer-supplier social capital, cluster social capital, buyer-supplier integration, cluster cooperation and supply risk in the context of SMEs. Many authors in the field of supply chain management have highlighted the importance of clearly defining constructs and measurement items under various contexts to enhance stringency of the research ( $\mathrm{Li}$ et al. 2005; Chen \& Paulraj 2004). Given that development of a measurement instrument for the constructs is at the core of theory building (Venkatraman 1989), we intend to contribute to the development of supply risk and network resources constructs with a set of operational measurements. Towards this end, we have followed a very rigorous step-by-step process to minimize the errors of the measurements.
Therefore, the findings of this study provide a set of valid measures that can be subsequently applied in other context to extend or refine the conceptualization as well as operational measures. Such an effort reflects a cumulative theory-building perspective where advancement is made by successively examining the efficacy of the measures in varying theoretical networks (Cronbach 1971). Moreover, this study will allow researchers to examine various theoretical and conceptual models with any of the five constructs, developed in this research, in the contexts of SMEs.

The rest of the paper is organized as follows. In section 2 , we define the domain and dimensions of all the constructs. Section 3 describes the data collection procedures of this research, followed by a section on the measurement development process. 
Finally, section 5 discusses the implications and the limitations of this research.

\section{Domain and Dimensions of the Constructs}

Domain of a construct is usually a brief yet reasonable and acceptable representation of the concept of interest (Lewis et al. 2005). In this research we specified the domain and the dimensions of all the constructs from the extant literature because reviewing the literature to identify the domain and the dimensions of a construct is considered as a more appropriate technique (Lewis et al. 2005).

\section{Social Capital}

Social capital, which is available through social network, has been considered as a valuable resource (Granovetter 1992). Although a number of definitions of social capital exist in the literature (Inkpen \& Tsang 2005), we define social capital as "the sum of the actual and potential resources embedded within, available through, and derived from the network of relationships possessed by an individual or social unit"(Nahapiet \& Ghoshal 1998 , p. 243). We adopt this definition because it accommodates both individual and organizational social capital (Inkpen \& Tsang 2005) and provides a wider view of the subject (Carey et al. 2011). This view of social capital comprises three dimensions: structural, relational and cognitive social capital (Nahapiet \& Ghoshal 1998; Tsai \& Ghoshal 1998).

Structural capital refers to the frequency of the social interaction between the network members (Carey et al. 2011). It emphases the benefits of multiple social ties across different levels and functions among the firms within the network (Prasad et al. 2012). Relational capital is the extent of kind of personal relationship between the members (Nahapiet \& Ghoshal 1998; Tsai \& Ghoshal 1998). Relational capital includes trust, commitment, reciprocity, friendship and mutual respect that network members have developed with one another (Villena et al. 2011). Finally, cognitive capital is the level of common perspectives, such as shared values, philosophies, languages and understanding, between the members of the network (Coleman 1988).
This research focuses on two types of social capital - buyer-supplier social capital and cluster social capital - because both of these social capitals assist SMEs in mitigating their supply risks (Chowdhury et al. 2016). While buyer-supplier social capital refers to the network resources leveraged from the network of sourcing SMEs and their key suppliers (Carey et al. 2011), cluster social capital refers to the network resources derived from the network of similar SMEs operating within a particular geographical cluster (Inkpen \& Tsang 2005). This study provides the measures of all three dimensions of social capital for both buyer-supplier social capital and cluster social capital.

\section{Buyer-supplier Integration}

Effective supply management needs integration of key strategies within the process (Lambert \& Cooper 2000). Following the definition of Chen et al. (2004) and Das et al. (2006), this research defines buyer-supplier integration as the synchronisation of information, resources and activities of suppliers and buyer in an essence of cooperation to gain mutual benefits. Multidimensional measures, such as (1) information sharing, (2) resource sharing, and (3) supplier collaboration between the buying firms and its key suppliers, represent the buyer-supplier integration.

\section{Cluster Cooperation:}

Cluster cooperation can be defined as the situation whereby homogeneous firms within the cluster share timely and quality information, share resources, and take remedy actions jointly (Oprime et al. 2011). Cluster cooperation is especially important for SMEs as they do not have sufficient physical resources and knowledge to individually deal with all the uncertainties.

\section{Supply Risk}

In the classical decision theory, risk is conceptualized as "variation in the distribution of possible outcomes"(March \& Shapira 1987, p. 1404). Following the variation-based view, this study conceptualizes supply risk as deviations in inbound supply from the initial overall objectives (Chen et al. 2013; Kumar et al. 2010). These deviations can occur in the time of delivery, quality 
of products, quantity of products or overall requirements.

\section{Data Collection}

In this research, required data has been collected from the manufacturing SMEs in the apparel industry of Bangladesh, one of the major developing countries in terms of growth in Gross Domestic Product (GDP) (World Bank 2015). Bangladesh is chosen as a study country for a number of reasons. First, literature on operations research, particularly on supply risk mitigation, of developing countries is still relatively limited (Sodhi \& Tang 2014). Second, selecting a country from the developing world seems more appropriate for this research because SMEs in the developing countries are more inclined to rely on social capital to manage risks (Gao et al. 2011). Finally, SMEs play a very significant role in the economy of Bangladesh (Rahman et al. 2015; Chowdhury et al. 2013). SMEs in the apparel industry are chosen as the subjects because this industry has been contributing significantly - around $80 \%$ of the total export for the past few years - to the economy of Bangladesh (Ahmed et al. 2014). Considering the context, firms having a maximum of 250 employees are considered as SMEs (Industrial Policy, Government of Bangladesh,2010)

\section{Measurement Development Procedures}

In designing the instrument, we followed a rigorous step-by-step process adapted from Straub et al. (2004), Vogt et al. (2004) and Haynes et al. (1995) to minimize errors. Initially, measurement items of all the constructs were developed by reviewing the facets of similar constructs from previous studies(Straub et al. 2004). Then, three focus group meetings with some members of the survey populations were conducted to validate the developed instrument and to reveal any new constructs or facets that are specific to the target population of the study (Vogt et al. 2004; O'Brien 1993). After the focus group meetings, the instrument was modified and new items were added. The instrument was then shown to academics and members of the target population to establish its appropriateness, adequacy and clarity(Lewis et al. 2005). Following the suggestions of the reviewers, the instrument was revised again. Finally, an inter rater agreement survey was carried out to determine the relevancy of the items to the constructs (Lindell 2001).The process is depicted in Figure 2.

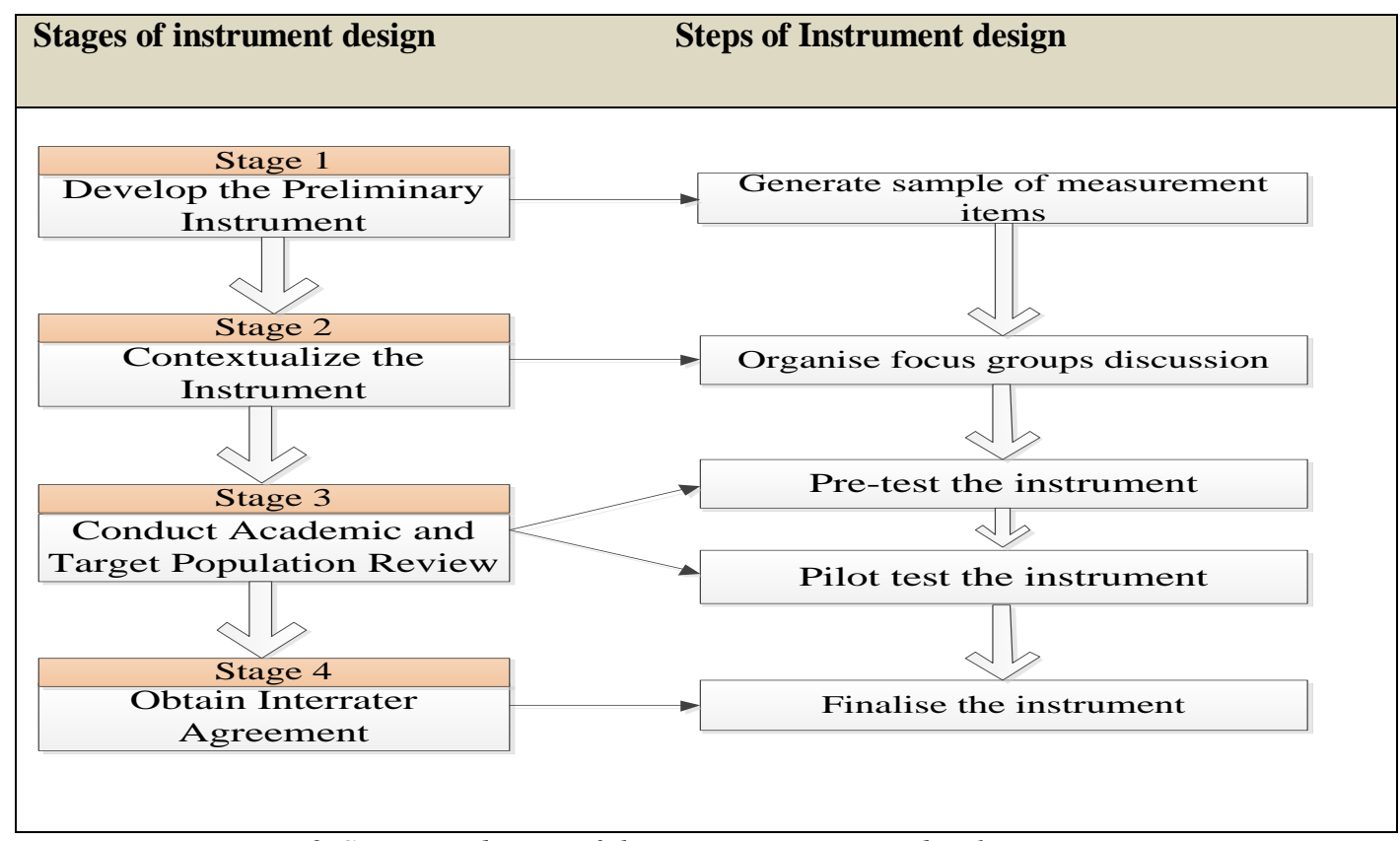

Figure2:Stages and steps of the survey instrument development process 


\section{Development of Preliminary Instrument:}

\section{Preliminary Measurement Items for Social Capital}

This study investigates two forms of social capital - buyer-supplier social capital and cluster social capital. Research that investigates two or more types of network capital generally uses the same items for different networks (Mesquita \& Lazzarini 2008; Schmitz 1999). Thus, same items were initially selected to measure both forms of social capital. However, they were referred in separate questions. Upon reviewing the extant literature, six items were selected to measure the structural social capital. These items are mainly concerned with the frequency of interactions and the multiple connections across diverse functions between the personnel of member organizations of the network. These interactions between network members include interactions in social events, joint workshop, co-location, team building exercises, interactions across different functions (Carey et al. 2011), and intensive interactions between the personnel (Villena et al. 2011). In order to measure the relational social capital six items were selected that examine the extent to which the relationship between the network members is characterized by trust, mutual respect, friendship, reciprocity, interpersonal communication and commitment (Carey et al. 2011; Krause et al. 2007; Kale et al. 2000). Finally, we selected five initial items to measure the cognitive social capital. These items examine the extent to which network members are congruent in organizational cultures, business philosophies, goals, ambition and vision, and codes and language(Johnson et al. 2013; Villena et al. 2011).

\section{Preliminary measurement Items for Buyer- supplier Integration}

Thirteen initial items measuring three dimensions information sharing, resource sharing and supplier collaboration - of buyer-supplier integration were initially selected to operationalize the construct. We selected four items from Prajogo \& Olhager (2012), Chen \& Paulraj (2004) and Chen et al. (2004) to measure the information sharing. These items measure the extent to which the buying SMEs and their key suppliers: (1) share sensitive information, (2) share any information that might help other party, (3) exchange information timely, accurately and/or completely, and (4) keep each other informed about events or changes that may affect other party. In order to operationalize the resource sharing, we selected four initial items from Yim \& Leem (2013) that examines the extent to which the buying SMEs and their key suppliers share: (1) business experiences, (2) technical supports, (3) tangible resources when necessary, and (4) financial resources. Finally, we selected five measurement items from $\mathrm{Li}$ et al. (2005) to examine the supplier collaboration. These items examine the extent to which SMEs (1) solve problem jointly with key suppliers, (2) help key suppliers to improve quality, (3) include key suppliers in improvement program, (4) include key suppliers in planning, and (5) involve key suppliers in product development.

\section{Preliminary Measurement Items for Cluster Cooperation}

Eight items were initially selected to measure the cluster cooperation that examine the extent to which SMEs within the cluster share information and resources, and take joint action to gain mutual benefits (Li \& Geng 2012; Schmitz 2000). These items are reflected in the cooperation with other SMEs within the cluster to: (1) exchange information, (2) share business experience, (3) exchange resources, (4) follow up the activities of each other, (5) take joint action to improve product quality, (6) organize labour training jointly, (7) use cooperative sourcing, and (8) solve common problem jointly.

\section{Preliminary Measurement items for Supply Risk}

This study uses the variance-based view in defining supply risk. We initially select six items to measures variation in inbound supply demonstrated through (1) quality, (2) quantity, (3) lead time, (4) overall requirements, (5) maintaining promise, and (6) capacity(Chen et al. 2013).

In summary, 61 items are initially selected from the extant literature to operationalize the constructs of this study.

\section{Contextualization of the Instrument}

Next, three focus group meetings with some members of the target populations - operation managers of apparel SMEs of Bangladesh - were 
organized to validate and modify measurements of constructs to enable a better fit in the context of the research (Vogt et al. 2004). In this research, the size of each focus group was five, which allowed the participants to involve more in the discussion as recommended in other studies (Neumark-Sztainer et al. 1999; Kitzinger 1995). The three group discussions lasted for 55 minutes, 69 minutes and 71 minutes respectively. As the same issues and topics identified in the first and the second meetings also emerged in the third meeting and there was no new finding, the point of saturation was reached and the focus group discussions were considered completed (Morgan 1997). All the sessions were audio recorded with the permission of the participants to facilitate the coding and the analysis of the data (Owen et al. 2016; Kidd \& Parshall 2000). From the analysis of the focus group data, thirteen new items were added under four constructs - buyer-supplier social capital, cluster social capital, buyer-supplier integration and supply risk. Respondents endorsed the measurement items of cluster cooperation construct but they did not provide any new item.

\section{Buyer-supplier Social Capital}

Two new items were identified under the construct of buyer-supplier structural capital. These are: (1) SMEs interacts with their suppliers face-to-face, and (2) SMEs interacts with the suppliers via multiple channels. Respondents of all three focus group meetings mentioned about these two items. For example, one of the participants of the first group meeting mentioned that "we physically go to the suppliers' house to buy the material, although we know they will deliver it to us if we order through mobile". Another respondent of the first group meeting said that "in addition to face-to-face interaction, we communicate with the key suppliers in different ways: sometimes we call them, sometimes we use social media to communicate with them, and sometimes we use email to interact with them".

One additional item was added in this stage to buyer-supplierrelational capital. One of the respondents in the second group meeting mentioned that "we always value the best interest of the relationship; we try to avoid any behaviour that may harm the other party". Thus, one item that relates to the togetherness in the relationship between SMEs and their key suppliers was added to the buyer-supplier relational capital. One item was also added to the buyer-supplier cognitive capital. Respondents in the first group meeting mentioned that "Most of our supplying firms are also small firms like us; hence we understand each other substantially". Similar discussion also emerged from the second group meeting; hence the measurement item - buying SMEs and their key suppliers share the similar resources/capabilities was added to the buyer-supplier cognitive capital.

\section{Buyer-supplier Integration}

Three initial dimensions - information sharing, resource sharing and supplier collaboration - of buyer-supplier integration were supported as the dimensions of buyer-supplier integration by the respondents of the groups meeting. One more dimension - flexible sourcing - was identified at this stage as respondents of all three groups discussion mentioned about fulfilling sudden needs and modifying the orders. For instance, one of the respondents of the second group meeting mentioned that "if we need something urgently, we just make a call to our key suppliers and they take all necessary actions to deliver the materials to our factory". Based on the findings of all three group meetings, four items were identified to operationalize the flexible souring. They include: (1) firms can make quick orders, (2) firms can modify the order specification, (3) firms can modify the delivery time, and (4) suppliers take necessary actions to fulfil sudden needs.

\section{Cluster Social Capital}

Discussions with the respondents in all three group meetings revealed that firms within a cluster interact quite frequently in different ways with other firms to build personal relationships. For instance, one of the respondents of the second group meeting mentioned that "as we are doing business in the same area, we frequently take lunch or go to the mosque together for the prayers; this kind of social interaction improves the bonding between us". Consequently, one item - firms within a cluster interact in the various daily activities - was added to the measurement of structural cluster capital. One measurement item was also added to the cluster relational capital that relates to togetherness, as the respondents of the second and the third focus groups clearly mentioned that they valued the collective benefit of 
the cluster, and together with other firms they were trying to develop the whole cluster. For instance, one of the respondents of the third focus group mentioned that "despite all of us (the firms) in this apparel cluster are doing the same business, we work hard together to develop the image of this cluster. We believe if we can work together, we can improve the reputation of the cluster and can attract more buyers." Two items were also added to the cluster cognitive capital to measure the extent to which: (1) firms within a cluster use the same terms and jargons, and (2) employees of the firms within a cluster have similar professional and trade skills. Respondents of the second and the third group meetings mentioned the first item while respondents of all three groups mentioned the second item. For instance, in the second group meeting, one of the respondents mentioned that "as we all are based in the same area, we always use the same terms and jargons". One of the respondents in the first group meeting mentioned that "employees of all the firms in this area have similar skills because we are doing the same business and producing identical products".

\section{Supply Risk}

In addition to the measurement items identified from the literature review, respondents of the group meetings mentioned about the deviation in price in sourcing. For instance, one of the respondents of the first group meeting mentioned that "sometimes we face problem due to the frequent price increases by the suppliers. For example, I bought some materials from a supplier last week and when I returned a couple of days later to buy some additional materials the price had increased". Therefore, it was added as a measurement item for supply risk.

In summary, through the focus group discussions, thirteen new items were added to the instrument, giving a total of 74 items to operationalize the constructs of this research.

\section{Academic and Target Population Review}

\section{Pre-testing the Instrument}

The instrument of this study was pretested by the academics to examine whether the instrument accomplishes the study objectives (Forza 2002). The instrument was pre-tested in two phases. First, the English version of the questionnaire was presented to three academics to ensure that the instrument measures all the constructs appropriately and adequately. Some modifications were made with the scaling and anchoring of the questions in the questionnaire. The questionnaire was then translated into Bangla, the mother language of Bangladesh, by a professional interpreter. At the second phase, the translated questionnaire was presented to five local academics to comment on the questions in the instrument in terms of their relevancy, adequacy and clarity. Some minor modifications were also made with the wording of the questions.

\section{Pilot Testing the Instrument}

At this stage, the researchers physically visited five samples of the target population, and questionnaire was presented to them face-to-face(Schwarz et al. 1991). Respondents were asked to review whether (1) definitions of constructs are clear, (2) wording and meaning of the questions are clear, and (3) there is any likely problem in answering the questions. Based on the comments of the respondents, some minor revisions were made to ensure that the questions and instructions are clear and user friendly.

\section{Interrater Agreement Survey}

Finally, an interrater agreement survey was carried out to determine the relevancy of the items to the constructs and ensure the further content validity(Haynes et al. 1995).A five-point Likert scale ranging from 'not relevant' to 'absolutely relevant' for all 74 items of the instruments is used in this study (Banerjee 1999). Using 10 or more raters is suggested for the interrater agreement survey (Lindell et al. 1999). In this study 20 interrater survey questionnaires were distributed and collected from the respondents to ensure more consistent results (Lindell 2001).From the responses of the judges, a mean score was computed to represent the extent to which a particular item is relevant to a construct (Polit \& Beck 2006). If the mean value of an item is less than half of the maximum scale point (i.e. 2.5 in this case), that item is considered irrelevant to the construct (Shoukri 2010; Davis 1992), and should be deleted from the instrument (Lindell 2001). Mean score of all the items of the instrument of this 
study is more than 2.5 (appendix 1), thus all of them are retained for further analysis.

If an item receives more than half of the maximum possible mean score, then it should be further analyzedthrough investigating the power and the pvalue of the items to examine the consensus of the agreement among the raters (Preston \& Colman 2000; Lindell \& Brandt 1997). In the situation when judges rate multiple items of a single target, Lindell (2001) have developed the mathematical equation to calculate the index of interrater agreement $\left(r *_{w g}\right)$. The recommended equation for calculating the interrater agreement is as following;

where

$$
r *_{w g(J)}=1-\left(\frac{s_{n}^{-2}}{s_{E U}^{2}}\right)
$$

$\mathrm{J}$ is the number of items

$s_{n}^{-2}$ is the variance of the ratings of judges

$s_{E U}^{2}$ is the variance of the uniform distribution

Based on the index of interrater agreement, $p$-value and power of each of the items were calculated. An item, which sustains through the evaluation of the mean value, is dropped from the instrument if the p-value of the item is more than 0.05 and/or the power is less than 0.8 (Sud-on et al. 2013). Summarizing the discussion above, the decision regarding dropping the items was taken based on the following criteria-

1) Drop item when its mean value is less than the midpoint.

2) Drop items left from 1) when $\mathrm{p}>.05$.

3) Drop items left from 2) when power $<0.8$.

The results of the interrater agreement analysis (appendix 1) demonstrate that altogether 10 items of this study received $\mathrm{p}$-value more than 0.05 and/or power less than 0.8. These 10 items were dropped from the instrument. The final instrument, therefore, contains 64 items used to measure the four constructs of network resources and supply risk constructs. Appendix 1 includes all the items to operationalize these five constructs.

\section{Discussion and Conclusion}

This study presented the development of the operational measures for four network resources constructs and supply risk construct in the context of SMEs. During the construct validation process, thirteen new items and one sub-construct were added with the preliminary instrument which was developed based on literature review. However, during the purification process, 10 items were deleted for improving the content validity of the constructs. Deletion of these 10 items does not affect the underlying theoretical construct. Their deletion only reflects that these items are not important in the context of SMEs.

The major contribution of the present study is the provision of a rigorously validated instrument for of a set of constructs related to network resources and supply risk in the context of SMEs. We believe the measures developed in this research are valid and can be used for further studies on network resources and their relationship with other outcome constructs, such as operational performance, knowledge creation and knowledge sharing. Although, many scholars suggested that social capital can play a very significant role in mitigating the risks of SMEs, there is alack in the understanding of what constitutes a comprehensive set of network capital constructs. The measures of four network resources constructs - buyer-supplier social capital, cluster social capital, buyer-supplier integration and cluster cooperation - provided in this paper can be useful to SME practitioners in evaluating their state of network capitals. These measures can help them formulate proper strategies to leverage various types and dimensions of network capitals.

In the present work, data was only collected from SMEs in Bangladesh. Future studies can broaden their scope by collecting data from various developing and developed countries. This is because measures developed in this study may not be appropriate for the SMEs in developed countries as they are relatively IT savvy and provided with formal training opportunities (Tang et al. 2015; Kartiwi \& MacGregor 2007). Since the concept of social capital can be studied in the context of various networks (Inkpen \& Tsang 2005), a single study may not be able to cover the domain of various networks. In this study, we only focused on two networks - network between sourcing SMEs and their key suppliers, and network of peers operating within a geographical cluster. Future studies can develop measures of social capital for other networks, such as manufactures with their customers, subsidiaries working under a unified business identity, and manufacturers with different logistics service providers. Another direction for 
further study is that dimensionality, convergent and discriminant validity of the constructs can be checked through quantitative analyses, such as exploratory factor analysis or confirmatory factor analysis. A large-scale survey can be conducted to test the dimensionality, convergent and discriminant validity of the developed constructs.

\section{Appendix: 1}

Measurement of Constructs with the results of interrater agreement analysis

\begin{tabular}{|c|c|c|c|c|c|}
\hline Constructs & Items & Mean & $\begin{array}{c}\mathrm{p}- \\
\text { value }\end{array}$ & Power & Decision \\
\hline \multirow{8}{*}{$\begin{array}{l}\text { Buyer- } \\
\text { supplierStructural } \\
\text { Capital** }\end{array}$} & Intensive interaction between the personnel & 4.40 & 0.000 & 1.00 & $\sqrt{ }$ \\
\hline & Interaction between the personnel across different functions & 3.35 & 0.024 & 0.56 & Dropped \\
\hline & Interaction in the organized social and family events & 3.75 & 0.001 & 0.95 & $\sqrt{ }$ \\
\hline & Interaction in the joint workshop & 2.80 & 0.209 & 0.12 & Dropped \\
\hline & Interaction in the co-location & 4.10 & 0.004 & 0.86 & $\sqrt{ }$ \\
\hline & Interaction in the team building exercises & 3.40 & 0.071 & 0.32 & Dropped \\
\hline & Face to face interaction * & 4.25 & 0.000 & 0.99 & $\sqrt{1}$ \\
\hline & Interaction via multiple channels $*$ & 4.35 & 0.001 & 0.98 & $\sqrt{ }$ \\
\hline \multirow{7}{*}{$\begin{array}{l}\text { Buyer- } \\
\text { supplierRelational } \\
\text { Capital** }\end{array}$} & Trust between the partners & 4.50 & 0.000 & 1.00 & $\sqrt{ }$ \\
\hline & Mutual respect between the partners & 4.05 & 0.001 & 0.97 & $\sqrt{ }$ \\
\hline & Personal friendship between the partners & 3.90 & 0.004 & 0.86 & $\sqrt{ }$ \\
\hline & $\begin{array}{l}\text { Reciprocity (feelings of fairness to work mutually) between } \\
\text { the partners }\end{array}$ & 4.40 & 0.006 & 0.81 & $\sqrt{ }$ \\
\hline & Personal interaction between the partners & 3.65 & 0.005 & 0.82 & $\sqrt{ }$ \\
\hline & Commitment for working in the foreseeable future & 4.40 & 0.000 & 1.00 & $\sqrt{ }$ \\
\hline & Togetherness between the partners* & 4.00 & 0.004 & 0.85 & $\sqrt{ }$ \\
\hline \multirow{6}{*}{$\begin{array}{l}\text { Buyer- } \\
\text { supplierCognitive } \\
\text { Capital** }\end{array}$} & Similar corporate values & 4.45 & 0.000 & 1.00 & $\sqrt{ }$ \\
\hline & $\begin{array}{l}\text { Similar philosophies/approaches to business dealings and } \\
\text { management styles }\end{array}$ & 4.20 & 0.000 & 1.00 & $\sqrt{ }$ \\
\hline & Similar business goals & 3.70 & 0.021 & 0.58 & Dropped \\
\hline & Similar ambition and vision & 3.40 & 0.071 & 0.32 & Dropped \\
\hline & Similar business codes and language & 3.65 & 0.001 & 0.98 & $\sqrt{ }$ \\
\hline & Similar resources/capabilities of the business & 3.25 & 0.004 & 0.87 & $\sqrt{ }$ \\
\hline \multirow{4}{*}{$\begin{array}{l}\text { Information } \\
\text { Sharing** }\end{array}$} & $\begin{array}{l}\text { Buying firm and its key suppliers share sensitive } \\
\text { information }\end{array}$ & 3.85 & 0.001 & 0.98 & $\sqrt{ }$ \\
\hline & $\begin{array}{l}\text { Buying firm and its key suppliers share with each other any } \\
\text { information that might help other party }\end{array}$ & 4.35 & 0.000 & 1.00 & $\sqrt{ }$ \\
\hline & $\begin{array}{l}\text { Buying firm and its key suppliers exchange information } \\
\text { timely, accurately and/or completely }\end{array}$ & 4.65 & 0.000 & 1.00 & $\sqrt{1}$ \\
\hline & $\begin{array}{l}\text { Buying firm and its key suppliers keep each other informed } \\
\text { about events that may affect the other party }\end{array}$ & 4.10 & 0.000 & 1.00 & $\sqrt{ }$ \\
\hline \multirow{4}{*}{$\begin{array}{l}\text { Resource } \\
\text { Sharing** }\end{array}$} & $\begin{array}{l}\text { Buying firm and its key suppliers share business } \\
\text { experiences }\end{array}$ & 4.45 & 0.000 & 1.00 & $\sqrt{ }$ \\
\hline & Buying firm and its key suppliers share technical supports & 4.00 & 0.000 & 1.00 & $\sqrt{ }$ \\
\hline & $\begin{array}{l}\text { Buying firm and its key suppliers share equipment when } \\
\text { necessary }\end{array}$ & 3.40 & 0.013 & 0.67 & Dropped \\
\hline & Buying firm and its key suppliers share financial resources & 3.85 & 0.002 & 0.92 & $\sqrt{ }$ \\
\hline \multirow{5}{*}{$\begin{array}{l}\text { Supplier } \\
\text { Collaboration** }\end{array}$} & $\begin{array}{l}\text { Buying firm regularly solve problems jointly with its key } \\
\text { suppliers }\end{array}$ & 4.40 & 0.000 & 1.00 & $\sqrt{ }$ \\
\hline & $\begin{array}{l}\text { Buying firm have helped its key suppliers to improve their } \\
\text { product quality }\end{array}$ & 4.00 & 0.004 & 0.85 & $\sqrt{ }$ \\
\hline & $\begin{array}{l}\text { Buying firm have continuous improvement programs that } \\
\text { include its key suppliers }\end{array}$ & 3.35 & 0.012 & 0.69 & Dropped \\
\hline & $\begin{array}{l}\text { Buying firm include its key suppliers in planning and goal- } \\
\text { setting activities }\end{array}$ & 3.95 & 0.001 & 0.97 & $\sqrt{ }$ \\
\hline & $\begin{array}{l}\text { Buying firm actively involve its key suppliers in new } \\
\text { product development processes }\end{array}$ & 4.05 & 0.002 & 0.91 & $\sqrt{ }$ \\
\hline \multirow{3}{*}{$\begin{array}{l}\text { Flexible } \\
\text { Sourcing** }\end{array}$} & $\begin{array}{l}\text { Key suppliers allow the buying firm to make quick order } \\
\text { when necessary* }\end{array}$ & 4.10 & 0.001 & 0.95 & $\sqrt{ }$ \\
\hline & $\begin{array}{l}\text { Key suppliers allow the buying firm to modify the order } \\
\text { specifications when necessary* }\end{array}$ & 4.55 & 0.000 & 1.00 & $\sqrt{ }$ \\
\hline & $\begin{array}{l}\text { Key suppliers allow the buying firm to modify the delivery } \\
\text { time when necessary* }\end{array}$ & 3.90 & 0.004 & 0.86 & $\sqrt{ }$ \\
\hline
\end{tabular}




\begin{tabular}{|c|c|c|c|c|c|}
\hline & $\begin{array}{l}\text { Key suppliers take necessary actions to fulfil the sudden } \\
\text { needs of buying firm* }\end{array}$ & 4.55 & 0.000 & 1.00 & $\sqrt{ }$ \\
\hline \multirow{7}{*}{$\begin{array}{l}\text { Cluster Structural } \\
\text { Capital*** }\end{array}$} & Intensive interaction between the personnel & 4.25 & 0.001 & 0.95 & $\sqrt{ }$ \\
\hline & Interaction in the organized social and family events & 4.10 & 0.000 & 0.99 & $\sqrt{ }$ \\
\hline & Interaction in the joint workshop/training & 3.80 & 0.000 & 1.00 & $\sqrt{ }$ \\
\hline & Interaction between the personnel across different function & 3.65 & 0.005 & 0.82 & $\sqrt{ }$ \\
\hline & Interaction in the co-location & 4.00 & 0.001 & 0.94 & $\sqrt{1}$ \\
\hline & $\begin{array}{l}\text { Interaction in the cluster development meeting and } \\
\text { conferences }\end{array}$ & 4.45 & 0.000 & 1.00 & $\sqrt{ }$ \\
\hline & Interaction in the daily activities $*$ & 3.35 & 0.002 & 0.92 & $\sqrt{ }$ \\
\hline \multirow{7}{*}{$\begin{array}{l}\text { Cluster Relational } \\
\text { Capital*** }\end{array}$} & Trust between the members & 4.45 & 0.000 & 1.00 & $\sqrt{ }$ \\
\hline & Mutual respect between the members & 4.05 & 0.002 & 0.91 & $\sqrt{1}$ \\
\hline & Personal friendship between the members & 4.05 & 0.000 & 1.00 & $\sqrt{ }$ \\
\hline & $\begin{array}{l}\text { Reciprocity(feelings of fairness to work mutually) between } \\
\text { the members }\end{array}$ & 4.10 & 0.001 & 0.95 & $\sqrt{ }$ \\
\hline & Personal interaction between the members & 3.95 & 0.002 & 0.91 & $\sqrt{ }$ \\
\hline & Commitment for helping in the foreseeable future & 4.05 & 0.001 & 0.97 & $\sqrt{ }$ \\
\hline & Togetherness between the members* & 3.85 & 0.002 & 0.92 & $\sqrt{ }$ \\
\hline \multirow{7}{*}{$\begin{array}{l}\text { Cluster Cognitive } \\
\text { Capital*** }\end{array}$} & Similar culture and values & 4.45 & 0.000 & 1.00 & $\sqrt{ }$ \\
\hline & $\begin{array}{l}\text { Similar philosophies/ approaches to business dealings and } \\
\text { management styles }\end{array}$ & 4.50 & 0.000 & 1.00 & $\sqrt{ }$ \\
\hline & Similar business goals & 3.75 & 0.004 & 0.87 & $\sqrt{ }$ \\
\hline & Similar ambition and vision & 3.25 & 0.171 & 0.15 & Dropped \\
\hline & Similar codes and language & 4.10 & 0.000 & 0.99 & $\sqrt{1}$ \\
\hline & Common terms or jargons* & 3.90 & 0.000 & 0.99 & $\sqrt{ }$ \\
\hline & Similar professional or trade skills of employees* & 3.95 & 0.001 & 0.97 & $\sqrt{ }$ \\
\hline \multirow{8}{*}{$\begin{array}{l}\text { Cluster } \\
\text { Cooperation } * * *\end{array}$} & $\begin{array}{l}\text { Similar firms of the local area exchange information (e.g. } \\
\text { information about suppliers) }\end{array}$ & 4.50 & 0.000 & 1.00 & $\sqrt{ }$ \\
\hline & Similar firms of the local area exchange experiences & 4.55 & 0.000 & 1.00 & $\sqrt{ }$ \\
\hline & Similar firms of the local area share resources & 3.95 & 0.001 & 0.97 & $\sqrt{ }$ \\
\hline & $\begin{array}{l}\text { Similar firms of the local area can follow up the innovations } \\
\text { of each other }\end{array}$ & 3.40 & 0.025 & 0.54 & Dropped \\
\hline & $\begin{array}{l}\text { Similar firms of the local area take joint effort to improve } \\
\text { the quality of products }\end{array}$ & 3.50 & 0.014 & 0.66 & Dropped \\
\hline & $\begin{array}{l}\text { Similar firms of the local area jointly organize labour } \\
\text { training program to improve the employees' skills }\end{array}$ & 3.90 & 0.000 & 1.00 & $\sqrt{ }$ \\
\hline & $\begin{array}{l}\text { Similar firms of the local area use cooperative sourcing of } \\
\text { material and/or parts }\end{array}$ & 4.10 & 0.001 & 0.95 & $\sqrt{ }$ \\
\hline & $\begin{array}{l}\text { Similar firms of the local area take joint actions to solve the } \\
\text { problems }\end{array}$ & 4.10 & 0.000 & 0.99 & $\sqrt{ }$ \\
\hline \multirow{7}{*}{ Supply Risk } & Deviation of quality specified by buyer & 4.65 & 0.000 & 1.00 & $\sqrt{ }$ \\
\hline & Deviation of delivery lead times specified by buyer & 4.60 & 0.000 & 1.00 & $\sqrt{ }$ \\
\hline & Deviation of volume/quantity specified by buyer & 4.65 & 0.000 & 1.00 & $\sqrt{1}$ \\
\hline & Deviation of overall requirements specified by buyers & 4.15 & 0.002 & 0.92 & $\sqrt{ }$ \\
\hline & Break of promise by key suppliers in delivering material & 3.95 & 0.001 & 0.97 & $\sqrt{ }$ \\
\hline & Fluctuation of the capacity of key suppliers & 3.95 & 0.001 & 0.97 & $\sqrt{ }$ \\
\hline & Inconsistent price of the material* & 3.75 & 0.001 & 0.95 & $\sqrt{ }$ \\
\hline
\end{tabular}

* Items marked by an asterisk were added from the focus groups discussion.

**Constructs marked by two asterisks measured network resources in the network of sourcing SMEs and their key suppliers.

***Constructs marked by three asterisks measured network resources in the network of similar SMEs operating within a geographical cluster. 


\section{References}

Ahmed, F.Z., Greenleaf, A. \& Sacks, A., 2014. The paradox of export growth in areas of weak governance: The case of the ready made garment sector in Bangladesh. World Development, 56, pp.258-271.

Ambulkar, S., Blackhurst, J. \& Grawe, S., 2015. Firm's resilience to supply chain disruptions: Scale development and empirical examination. Journal of Operations Management, 33, pp.111-122.

Banerjee, M., 1999. Beyond kappa: a review of interrater agreement measures. Canadian Journal of Statistics, 27(1), pp.3-23.

Carey, S., Lawson, B. \& Krause, D.R., 2011. Social capital configuration, legal bonds and performance in buyer-supplier relationships. Journal of Operations Management, 29(4), pp.277-288.

Chen, I.J. \& Paulraj, A., 2004. Towards a theory of supply chain management: the constructs and measurements. Journal of Operations Management, 22(2), pp.119-150.

Chen, I.J., Paulraj, A. \& Lado, A.A., 2004. Strategic purchasing, supply management, and firm performance. Journal of Operations Management, 22(5), pp.505-523.

Chen, J., Sohal, A.S. \& Prajogo, D.I., 2013. Supply chain operational risk mitigation: a collaborative approach. International Journal of Production Research, 51(7), pp.2186-2199.

Cheng, T.C.E., Yip, F.K. \& Yeung, A.C.L., 2012. Supply risk management via guanxi in the Chinese business context: The buyers perspective. International Journal of Production Economics, 139(1), pp.3-13.

Chowdhury, P., 2012. A Closure Look to the Challenges of Micro and Small Enterprises in Bangladesh and Counteractions against the Challenges. Kushagra International Management Review, 2(2), p.18.

Chowdhury, P., Lau, K.H. \& Pittayachawan, S., 2016. Supply risk mitigation of small and medium enterprises: A social capital approach. In The Proceedings of 21st International Symposium on Logistics. Centre for Concurrent Enterprise, Nottingham University, pp. 37-44.

Chowdhury, P., Zaman, F. \& and Hossain, M., 2013. Contribution of Micro and Small Enterprises of Bangladesh: An Empirical Study. Journal of Management Studies, 5(1\&2), pp.17-32.
Christopher, M. et al., 2011. Approaches to managing global sourcing risk. Supply Chain Management: An International Journal, 16(2), pp.67-81.

Coleman, J.S., 1988. Social Capital in the Creation of Human Capital. American Journal of Sociology, 94, pp.S95-S120.

Cronbach, L.J., 1971. Test validation. In R. L. Thorndike, ed. Educational Measurement, second ed. Washington, DC: American Council on Education, pp. 443-507.

Das, A., Narasimhan, R. \& Talluri, S., 2006. Supplier integration-finding an optimal configuration. Journal of Operations Management, 24(5), pp.563-582.

Davis, L.L., 1992. Instrument review: Getting the most from a panel of experts. Applied Nursing Research, 5(4), pp.194-197.

Ellegaard, C., 2008. Supply risk management in a small company perspective. Supply Chain Management: An International Journal, 13(6), pp.425-434.

Forza, C., 2002. Survey research in operations management: a process-based perspective. International Journal of Operations \& Production Management, 22(2), pp.152-194.

Gao, S.S., Sung, M.C. \& Zhang, J., 2011. Risk management capability building in SMEs: a social capital perspective. International Small Business Journal, 31(6), pp.677-700.

Granovetter, M.S., 1992. Economic institutions as social constructions: A framework for analysis. Acta Sociologica, 35(1), pp.3-11.

Haynes, S.N., Richard, D. \& Kubany, E.S., 1995. Content validity in psychological assessment: A functional approach to concepts and methods. Psychological Assessment, 7(3), p.238.

Hendricks, K.B. \& Singhal, V.R., 2005. Association between supply chain glitches and operating performance. Management Science, 51(5), pp.695-711.

Hendricks, K.B. \& Singhal, V.R., 2003. The effect of supply chain glitches on shareholder wealth. Journal of Operations Management, 21(5), pp.501522.

Inkpen, A.C. \& Tsang, E.W.K., 2005. Social capital, networks, and knowledge transfer. The 
Academy of Management Review, 30(1), pp.146165.

Jansen, R.J.G. et al., 2011. Information processing and strategic decision-making in small and medium-sized enterprises: The role of human and social capital in attaining decision effectiveness. International Small Business Journal, 31(2), pp.192-216.

Johnson, N., Elliott, D. \& Drake, P., 2013. Exploring the role of social capital in facilitating supply chain resilience. Supply Chain Management: An International Journal, 18(3), pp.324-336.

Kale, P., Singh, H. \& Perlmutter, H., 2000. Learning and protection of proprietary assets in strategic alliances: Building relational capital. Strategic Management Journal, 21(3), pp.217-237.

Kartiwi, M. \& MacGregor, R.C., 2007. Electronic commerce Adoption barriers in small to Mediumsized Enterprises ( SMEs ) in Developed and Developing countries: A cross-country comparison. Journal of Electronic Commerce in Organizations, 5(3), pp.35-51.

Kidd, P.S. \& Parshall, M.B., 2000. Getting the focus and the group: Enhancing analytical rigor in focus group research. Qualitative health research, 10(3), pp.293-308.

Kim, Y. \& Vonortas, N.S., 2014. Managing risk in the formative years: Evidence from young enterprises in Europe. Technovation, 34(8), pp.454-465.

Kitzinger, J., 1995. Qualitative research. Introducing focus groups. BMJ: British medical journal, 311(7000), p.299.

Krause, D.R., Handfield, R.B. \& Tyler, B.B., 2007. The relationships between supplier development, commitment, social capital accumulation and performance improvement. Journal of Operations Management, 25(2), pp.528-545.

Kumar, S.K., Tiwari, M.K.K. \& Babiceanu, R.F., 2010. Minimisation of supply chain cost with embedded risk using computational intelligence approaches. International Journal of Production Research, 48(13), pp.3717-3739.

Lambert, D.M. \& Cooper, M.C., 2000. Issues in supply chain management. Industrial Marketing Management, 29(1), pp.65-83.

Lewis, B.R., Templeton, G.F. \& Byrd, T.A., 2005. A methodology for construct development in MIS research. European Journal of Information Systems, 14(4), pp.388-400.
Li, J. \& Geng, S., 2012. Industrial clusters, shared resources and firm performance. Entrepreneurship \& Regional Development, 24(5-6), pp.357-381.

Li, S. et al., 2005. Development and validation of a measurement instrument for studying supply chain management practices. Journal of Operations Management, 23(6), pp.618-641.

Lindell, M.K., 2001. Assessing and testing interrater agreement on a single target using multiitem rating scales. Applied Psychological Measurement, 25(1), pp.89-99.

Lindell, M.K. \& Brandt, C.J., 1997. Measuring interrater agreement for ratings of a single target. Applied Psychological Measurement, 21(3), pp.271-278.

Lindell, M.K., Brandt, C.J. \& Whitney, D.J., 1999. A revised index of interrater agreement for multiitem ratings of a single target. Applied Psychological Measurement, 23(2), pp.127-135.

March, J.G. \& Shapira, Z., 1987. Managerial perspectives on risk and risk taking. Management Science, 33(11), pp.1404-1418.

Mesquita, L.F. \& Lazzarini, S.G., 2008. Horizontal and vertical relationship in developing economies: Implications for SMEs' access to global markets. Academy of Management Journal, 51(2), pp.359380.

Nahapiet, J. \& Ghoshal, S., 1998. Social capital , intellectual capital and the organizational advantage. The Academy of Management Review, 23(2), pp.242-266.

Neumark-Sztainer, D. et al., 1999. Factors influencing food choices of adolescents: findings from focus-group discussions with adolescents. Journal of the American dietetic association, 99(8), pp.929-937.

O’Brien, K., 1993. Improving survey questionnaires through focus groups. In D. L. Morgan, ed. Successful Focus Groups: Advancing the State of the Art. Sage Publications, Inc, pp. 105-117.

Oprime, P.C., Tristao, H.M. \& Pimenta, M.L., 2011. Relationships, cooperation and development in a Brazilian industrial cluster. International Journal of Productivity and Performance Management, 60(2), pp.115-131.

Owen, N., Fox, A. \& Bird, T., 2016. The development of a small-scale survey instrument of UK teachers to study professional use (and nonuse) of and attitudes to social media. International Journal of Research \& Method in Education, 39(2), 
pp.170-193.

Polit, D.F. \& Beck, C.T., 2006. The Content Validity Index: Are You Sure You Know What's Being Reported? Critique and Recommendations. Research in nursing \& health, 31(29), pp.489-497.

Prajogo, D. \& Olhager, J., 2012. Supply chain integration and performance: The effects of longterm relationships, information technology and sharing, and logistics integration. International Journal of Production Economics, 135(1), pp.514522.

Prasad, S., Tata, J. \& Guo, X., 2012. Sustaining small businesses in the United States in times of recession: Role of supply networks and social capital. Journal of Advances in Management Research, 9(1), pp.8-28.

Preston, C.C. \& Colman, A.M., 2000. Optimal number of response categories in rating scales: reliability, validity, discriminating power, and respondent preferences. Acta Psychologica, 104, pp.1-15.

Rahman, M.Z., Chowdhury, P. \& Sarkar, A., 2015. Successful Customer Relationship Management: A study on Micro, Small and Medium Enterprises. Splint International Journal of Professionals, 2(2), pp.1-12.

Schmitz, H., 2000. Does local co-operation matter? Evidence from industrial clusters in South Asia and Latin America. Oxford Development Studies, 28(3), pp.323-336.

Schmitz, H., 1999. Global competition and local cooperation: success and failure in the Sinos Valley, Brazil. World Development, 27(9), pp.1627-1650.

Schwarz, N. et al., 1991. The impact of administration mode on response effects in survey measurement. Applied Cognitive Psychology, 5(3), pp.193-212.

Shoukri, M.M., 2010. Measures of Interobserver Agreement and Reliability, Boca Raton: CRC Press.

Sodhi, M.S. \& Tang, C.S., 2014. Supply chain research opportunities with the poor as suppliers or distributors in developing countries. Production and Operations management, 23(9), pp.1483-1494.

Straub, D., Boudreau, M.-C. \& Gefen, D., 2004. Validation guidelines for IS positivist research. The Communications of the Association for Information Systems, 13(1), pp.380-427.

Sud-on, P. et al., 2013. Manufacturing Agility:
Construct and Instrument Development. World Academy of Science, Engineering and Technology, 82, pp.754-762.

Tang, C.S., Wang, Y. \& Zhao, M., 2015. The Implications of Utilizing Market Information and Adopting Agricultural Advice for Farmers in Developing Economies. Production and Operations Management, 24(8), pp.1197-1215.

Tsai, W. \& Ghoshal, S., 1998. Social Capital and Value Creation: The Role of Intrafirm Networks. The Academy of Management Journal, 41(4), pp.464-476.

Uphoff, N., 2000. Understanding social capital: learning from the analysis and experience of participation. Social capital: A Multifaceted Perspective, pp.215-249.

Venkatraman, N., 1989. Strategic orientation of business enterprises: The construct, dimensionality, and measurement. Management Science, 35(8), pp.942-962.

Villa, A. \& Antonelli, D., 2009. A road map to the development of European SME networks: Towards collaborative innovation, Springer-Verlag London Limited.

Villena, V.H., Revilla, E. \& Choi, T.Y., 2011. The dark side of buyer-supplier relationships: A social capital perspective. Journal of Operations Management, 29(6), pp.561-576.

Vogt, D.S., King, D.W. \& King, L.A., 2004. Focus groups in psychological assessment: enhancing content validity by consulting members of the target population. Psychological Assessment, 16(3), p.231.

Wiengarten, F., Pagell, M. \& Fynes, B., 2013. The importance of contextual factors in the success of outsourcing contracts in the supply chain environment: the role of risk and complementary practices. Supply Chain Management-an International Journal, 18(6), pp.630-643.

World Bank, 2015. Bangladesh Development Update, April 2015, Washington: The World Bank. Available at: http://wwwwds.worldbank.org/external/default/WDSContentS erver/WDSP/IB/2015/08/10/090224b082df902f/1 0/Rendered/PDF/Bangladesh0dev00update00April 020150.pdf.

Yim, B. \& Leem, B., 2013. The effect of the supply chain social capital. Industrial Management \& Data Systems, 113(3), pp.324-349. 